\title{
The Relationship between Grade 9 Teacher's and Learner's Perceptions and Attitudes with Their Mathematics Achievement
}

\section{Mathelela Steyn Mokgwathi}

Department of Science, Mathematics and Technology Education, Faculty of Education, University of Pretoria, South Africa, steyn.mokgwathi@gmail.com

\section{Marien Alet Graham}

Department of Science, Mathematics and Technology Education, Faculty of Education, University of Pretoria, South Africa, marien.graham@up.ac.za

\section{William Fraser}

Prof., Department of Science, Mathematics and Technology Education, Faculty of Education, University of Pretoria, South Africa, william.fraser@up.ac.za

The study investigated the relationship between South African Grade 9 teachers' and learners' perceptions and attitudes with their mathematics achievement. The study used a secondary analysis of the TIMSS 2015 mathematics data, guided by the conceptual framework model of Scheerens (2000). The quantitative data collected through teachers' and learners' responses to the questionnaire included teachers' and learners' attitudes and perceptions on mathematics achievement. Multi-level modelling was done using HLM software. The study revealed that learners that like learning mathematics and value mathematics outperform those who don't like it and who don't value it. It was also found that leaners that are confident in mathematics outperformed those who are not confident. An interesting finding was that teacher job satisfaction has no influence on the mathematics achievement of their learners. Another curious finding was that the level of learner engagement in the mathematics lesson also had no influence on their performance.

Keywords: teacher and learner attitude, learner achievement, mathematics, TIMSS, secondary analysis, multi-level modeling

\section{INTRODUCTION}

Low learner achievement in mathematics has been a major concern for the Department of Education and other stakeholders. The low achievement in mathematics could be evidenced recently by the TIMSS 2011 and TIMSS 2015 study, Annual National Assessment (ANA) results as well as the National Grade 12 Examinations. Furthermore, South Africa participated in the Monitoring Learning Achievement (MLA) study as

Citation: Mokgwathi, M. S., Graham, M. A., \& Fraser, W. (2019). The Relationship between Grade 9 Teacher's and Learner's Perceptions and Attitudes with Their Mathematics Achievement. International Journal of Instruction, 12(1), 841-850. https://doi.org/10.29333/iji.2019.12154a 
early as 1991 and in international comparative studies such as the Southern African Consortium for Monitoring Educational Quality (SACMEQ) II and III in an attempt to address the learner achievement in mathematics and science which has been consistently low (Spaul, 2013). This study aims to identify specific teacher and learner attitudinal factors associated with Grade 9 learner achievement in mathematics as measured by the TIMSS 2015 study.

\section{PROBLEM STATEMENT}

The TIMSS studies follow a four-year cycle of assessment and South Africa participated in these studies since 1995. TIMSS created a set of international benchmarks to provide countries with a more meaningful description of what learners know (TIMSS, 2015). Therefore, learner achievement is reported against a set of established benchmarks. There are four groupings of benchmarks created, namely, the advanced international benchmark (625), the high international benchmark (550), the intermediate international benchmark (475) and the low international benchmark (400). These survey studies have a centre point of 500 established and scaled to remain constant for easy comparison between countries and between the years of assessment (Mullis, Martin, Foy \& Arora, 2012).

Sadly, South Africa has not fared well in these studies. In 1995, South Africa performed significantly lower than the low international benchmark of 400, and scored an average of 276. Moreover, in 1999, learners participating in the study scored an average of 275, and in 2002, they scored an average of 285, which was still substantially below the international centre point of 500. South Africa participated in all the TIMSS studies except for the year 2007. In the TIMSS 2011 study, the mathematics performance for Grade 9 had improved by only 63 points, from 285 to 352, which was way below the Intermediate international average of 475. In the TIMSS 2015 study, there was an improvement of 87 points, from 352 to 372 , which was still way below the international low benchmark. Furthermore, South Africa had performed poorly in the SACMEQ survey tests in 2001 and that had revealed a weakness in both efficiency and equity. Research is therefore required to investigate attitudinal factors having an effect on Grade 9 learner performance in mathematics as identified by the TIMSS 2015 study.

Based on the problem statement, this study investigated the relationship of the following classroom factors: Teacher/Learner Attitudes and Perceptions and Mathematics Learner Achievement in high schools as measured by TIMSS 2015. The rationale for that was to develop a full comprehension of the teacher and learner attitude factors which could have an effect on Grade 9 learners' achievement in mathematics in South Africa. This will help policy makers and curriculum advisers to develop strategies and curriculum policies that may address these effects.

\section{RESEARCH QUESTIONS}

The study was guided by the following research question:

What attitudinal factors of teachers and learners can be associated with Grade 9 learner achievement in mathematics in South African high schools and what effect do these factors have on the learner achievement in mathematics as measured by TIMSS 2015 ?

The research sub-questions were as follows: 
1. To what extent do teacher attitudes and perceptions affect the achievement of their Grade 9 learners in mathematics?

2. What is the relationship between learner attitudes and perceptions and their achievement in mathematics?

\section{LITERATURE REVIEW}

This section is a review of the critical points of the current knowledge that has been published on learner achievement in mathematics internationally as well as in South Africa.

Teacher attitude is generally defined in terms of teacher behaviour as well as teacher characteristics and how that can be related to their interaction with learners. As far back as 1976, Aiken referred to attitudes towards mathematics in a classic work in the area of mathematics education as being significant, because there was a corresponding relationship as far as the attitudes towards mathematics and mathematics achievement were concerned. Evans (2011) in his study revealed a positive relation between teacher' attitude and their self-efficacy. More recently, Hobri, Dafik and Hossain (2018) in their study revealed that, attitudes towards mathematics to be significant predictor of learners' mathematics performance.

In a study by Tella (2017) it was revealed that, teacher attitude had no significant correlation with learner achievement in mathematics. Interestingly, an earlier study by Kiwanuka, Van Damme, Van Den Noortgate, Anumendem, Vanlaar, Reynolds and Namusis (2016), revealed a negative correlation between teacher attitude on learner performance.

\section{CONTEXT FOR THE STUDY}

The focus of this study was on South Africa specifically because of the poor performance in mathematics and science as measured by both local and international studies. "South Africa is about 1.2 million square kilometres and is situated at the southernmost end of the African continent. It is bordered by Namibia, Botswana, and Zimbabwe to the north and Mozambique to the northeast. There is an estimated population of about 53,31 million (www.statssa.gov.za ).

\section{METHOD}

\section{Research Design}

To examine the effect of teacher and learner attitudes and perception on Grade 9 learner achievement in mathematics, the researcher conducted a secondary analysis of the TIMSS 2015 data. A quantitative approach was followed to establish the relationship between the teacher and learner attitudes and perceptions (independent variables) and learner achievement in mathematics (dependent variable). Gender was also included in the study as an independent variable, since it has (typically) been found in the literature that gender plays a role in learner achievement (Butakor (2015), Ayieko, Gokbel and Nelson (2017)). The study was guided by the post-positivist theory (Maree, 2010) which assumes that reality is multiple, subjective and mentally constructed by individuals, therefore, not a fixed entity but to a certain degree it is accepted that reality is a creation of individuals involved in the research. Furthermore, post-positivism is built on the premise that the outcomes of the research are pivotal to the improvement of practice. 
That is why TIMSS not only measures mathematics performance (which would be typically positivist), but also relies on background information on attitudes and behaviours towards mathematics as constructed by learners and teachers.

\section{RESEARCH METHODS}

This study is a secondary analysis of data from TIMSS collected in 2015. Multi-level modelling was done using HLM software.

\section{Participants}

A total of 12514 learners were sampled in South Africa during the TIMSS 2015 study. The TIMSS 2015 study followed a two-stage stratified cluster sampling design wherein schools were sampled at the first stage and intact classes at the second stage of sampling (TIMSS, 2015). All samples were explicitly stratified by poverty level, public/private and census region. A systematic sample was selected independently in each stratum with sampling probabilities proportional to measures of size, where the measure of size is the estimated number of learners in Grade 9 (Kastberg, Roey, Ferraro \& Lemanski, 2013).

\section{Instruments}

TIMSS assessment consists of a large pool of mathematics and science questions, also known as items. The instruments used in the TIMSS 2015 study, that were relevant for the purposes of this study, were the school, teachers and learners' questionnaires, with the test items specifically chosen based on their relevance to the research questions. In TIMSS, learners completed achievement tests in mathematics and answered questions on their home background, prior experience and their attitudes towards mathematics. Furthermore, mathematics teachers completed questionnaires on their teaching preparations, teaching styles, professional development and attitudes towards mathematics. Principals and Head of Departments completed school questionnaires on school characteristics, parental involvement, Grade 9 teaching and teachers of mathematics, learner behaviour and resources and technology.

The TIMSS 2015 testing items were subjected to reliability testing, making use of the Cronbach's Alpha, a measure of internal consistency to determine the relationship between the testing items on the questionnaire with the variable under study (TIMSS, 2015). The reliability coefficients were computed for each item for every participating country. The Cronbach's Alpha reliability coefficients were accepted at the level above 0.6 (Field, 2014). In this study, reliability of selected variables was established once more to ensure that any reports from the independent variables, as taken from the background questionnaires, yielded to acceptable reliability coefficients as measured by Cronbach's Alpha. The learner, teacher as well as school items assessing teachers and learner attitudes and perceptions are given in Appendices 1 and 2, respectively, so that the reader can gain access to them.

Validity issues in this study, the teacher and learner as well as the school items are attached as Appendices 1 and 2 to ensure face validity. Only the section of the questionnaire which covers the variables identified for the study is attached to ensure content validity. In this study, an item analysis was conducted as the statistical technique to ensure construct validity. 


\section{Data Collection}

The original data of TIMSS 2015 were collected using a survey research design. TIMSS studies follow a block test design wherein items in for the questionnaire are arranged into blocks of items and these blocks are distributed between 14 test booklets. There are too many items that make up the TIMSS test and this means that learners will not be able to complete all items during the assessment. However, to attach the total score to each learner as though they had completed all items; TIMSS use Item Respond Theory (IRT) to estimate learner scores. Data was collected from teachers' and learners' responses to the questionnaires. The TIMSS 2015 data can be accessed from the following URL: www.iea.org.

\section{Research Procedures}

Permission was requested from, and granted by the Human Science Research Council (HSRC) to work with the TIMSS 2015 data.

\section{Data Analysis}

The study used the IDB Analyzer in order to merge the TIMSS datasets correctly. Following this, HLM (Hierarchical Linear Modeling) software was used for multi-level modelling. For this study we considered 5 student predictor variables at Level 1 and 2 teacher predictor variables at Level 2.

\section{FINDINGS}

The results of the exploration of teacher and learner attitude factors, as described in the research question section, are as follows:

The main research question, as stated in the introduction, is "What attitudinal and perceptual factors of teachers and learners can be associated with Grade 9 learner achievement in mathematics in South Africa high schools and what is the effect of these factors on the performance of mathematics as measured by TIMSS 2015?" The learner and teacher questionnaire had a large number of variables addressing the classroom factors.

The questions of interest (in the TIMSS 2015 questionnaires) are given in Tables 1 and 2 for teachers and learners, respectively.

Table 1

Questions for the teacher questionnaire

\begin{tabular}{|c|c|c|}
\hline Variable & Index & Question on questionnaire \\
\hline BTBG10A & \multirow{7}{*}{ Teacher job satisfaction } & I am content with my profession as a teacher \\
\hline BTBG10B & & I am satisfied with being a teacher at this school \\
\hline BTBG10C & & I find my work full of meaning and purpose \\
\hline BTBG10D & & I am enthusiastic about my job \\
\hline BTBG10E & & My work inspires me \\
\hline BTBG10F & & I am proud of the work I do \\
\hline BTBG10G & & I am going to teaching for as long as I can \\
\hline
\end{tabular}


Table 2

Questions on the learner questionnaire

\begin{tabular}{|c|c|c|}
\hline Variable & Index & Question on questionnaire \\
\hline BSBM17A & \multirow{9}{*}{$\begin{array}{l}\text { Students like } \\
\text { learning } \\
\text { mathematics }\end{array}$} & I enjoy learning mathematics \\
\hline BSBM17B & & I wish I did not have to study mathematics \\
\hline BSBM17C & & Mathematics is boring \\
\hline BSBM17D & & I learn many interesting things in mathematics \\
\hline BSBM17E & & I like mathematics \\
\hline BSBM17F & & I like any schoolwork that involves numbers \\
\hline BSBM17G & & I like to solve mathematics problems \\
\hline BSBM17H & & I look forward to mathematics class \\
\hline BSBM17I & & Mathematics is one of my favorite subjects \\
\hline BSBM18A & \multirow{10}{*}{$\begin{array}{l}\text { Engage } \\
\text { Teaching In } \\
\text { Math Lesson }\end{array}$} & I know what my teacher expects me to do \\
\hline BSBM18B & & My teacher is easy to understand \\
\hline BSBM18C & & I am interested in what my teacher says \\
\hline BSBM18D & & My teacher gives me interesting things to do \\
\hline BSBM18E & & My teacher has clear answers to my questions \\
\hline BSBM18F & & My teacher is good at explaining mathematics \\
\hline BSBM18G & & My teacher lets me show what I have learned \\
\hline BSBM18H & & My teacher does a variety of things to help us learn \\
\hline BSBM18I & & My teacher tells me how to do better when I make a mistake \\
\hline BSBM18J & & My teacher listens to what I have to say \\
\hline BSBM19A & \multirow{9}{*}{$\begin{array}{l}\text { Student } \\
\text { Confident In } \\
\text { Mathematics }\end{array}$} & I usually do well in mathematics \\
\hline BSBM19B & & Mathematics is more difficult for me than for many of my classmates \\
\hline BSBM19C & & Mathematics is not one of my strengths \\
\hline BSBM19D & & I learn things quickly in mathematics \\
\hline BSBM19E & & Mathematics makes me nervous \\
\hline BSBM19F & & I am good at working out difficult mathematics problems \\
\hline BSBM19G & & My teacher tells me I am good at mathematics \\
\hline BSBM19H & & Mathematics is harder for me than any other subject \\
\hline BSBM19I & & Mathematics makes me confused \\
\hline BSBM20A & \multirow{9}{*}{$\begin{array}{l}\text { Student Value } \\
\text { Mathematics }\end{array}$} & I think learning mathematics will help me in my daily life \\
\hline BSBM20B & & I need mathematics to learn other school subjects \\
\hline BSBM20C & & I need to do well in mathematics to get into the university of my choice \\
\hline BSBM20D & & I need to do well in mathematics to get the job I want \\
\hline BSBM20E & & I would like a job that involves using mathematics \\
\hline BSBM20F & & It is important to learn about mathematics to get ahead in the world \\
\hline $\mathrm{G}$ & & $\begin{array}{l}\text { Learning mathematics will give me more job opportunities when I am } \\
\text { an adult }\end{array}$ \\
\hline BSBM20H & & My parents think that it is important that I do well in mathematics \\
\hline BSBM20I & & It is important to do well in mathematics \\
\hline
\end{tabular}

International Journal of Instruction, January $2019 \bullet$ Vol.12, No.1 
The questions (for each index) are very highly correlated. It is well-known that when you add several highly correlated variables to a multi-level model, one of them would take up most of the accounted variance and the others will appear to be insignificant, but all that's happening is that the 'stronger' variable is taking up the influence, and the additional contribution of the next variable appears to be small. Thus, instead of adding these highly correlated variables individually, one adds the existing index variable instead. Accordingly, we worked with the existing index variables and added the variable for gender.

First, we start with the null model which is the unconditional model with no predictor variables at Level 1 and Level 2. The results of the null model are reported in Table 3. The variance at the student level is 3968.68, which represents $45.8 \%$ of the total variance. The variance at the teacher level is 3348.82, which represents $54.2 \%$ of the total variance. Also, the variance at the teacher level is significantly different from zero, since the p-value $<0.001$. The average reliability of school means for 2015 was 0.979 , which indicates that the sample means are highly reliable as indicators of the true school means.

Table 3

Summary output of the null model

\begin{tabular}{llllll}
\hline Random effect & $\begin{array}{l}\text { Standard } \\
\text { deviation }\end{array}$ & $\begin{array}{l}\text { Variance } \\
\text { component }\end{array}$ & df & Chi-square & p-value \\
\hline INTRCPT1 (u0) & 62.99 & 3968.68 & 291 & 13743.03 & 0.000 \\
\hline Level-1 (r) & 57.87 & 3348.82 & & & \\
\hline
\end{tabular}

After presenting the results from the null model, the results for the full model are shown in Table 4. The coefficients and their significance levels for all 5 learner variables and all 2 teacher variables for the full model are provided in Table 4.

Table 4

Coefficients and their significance levels for the full model

\begin{tabular}{lcccc}
\hline \multicolumn{1}{c}{ Variable } & Coefficient & $\begin{array}{c}\text { Standard } \\
\text { error }\end{array}$ & $\begin{array}{c}\text { t- } \\
\text { value }\end{array}$ & p-value \\
\hline Gender & Teacher variables (Level 2) & & & \\
\hline Teacher job satisfaction & -18.88 & 11.23 & -1.68 & 0.094 \\
\hline & 10.90 & 9.71 & -1.12 & 0.262 \\
\hline Gender & Student variables (Level 1) & & & \\
\hline Learner likes learning mathematics & -0.03 & 1.97 & -0.02 & 0.987 \\
\hline Engage teaching in math lesson & 10.03 & 1.46 & -6.87 & $0.000^{*}$ \\
\hline Learner confident in mathematics & -1.42 & 1.86 & 0.76 & 0.448 \\
\hline Learner value mathematics & 21.26 & 2.17 & -9.77 & $0.000^{*}$ \\
\hline
\end{tabular}

* Significant predictors $(\mathrm{p}$-value $<0.05)$ 
The full model explains $53.33 \%$ of the variance which is significant (p-value $<0.001$ ). On teacher level there were no significant predictors. On student level, three of the five predictors were significant. The more students like learning mathematics, the better they performed $(\beta=10.03$, $p$-value $<0.001)$. Students with higher confidence in mathematics outperformed students who have less confidence $(\beta=21.26$, p-value $<0.001)$. Students that value mathematics outperformed those who do not $(\beta=13.99$, $\mathrm{p}$-value $<0.001)$.

Since gender was not significant on either Level 1 or Level 2, it was removed from the model, so the focus of the final model is only placed on students' and teachers' perceptions and attitudes towards mathematics. The coefficients and their significance levels for the final model is shown in Table 5.

Table 5

Coefficients and their significance levels for the final model

\begin{tabular}{lcccc}
\hline \multicolumn{1}{c}{ Variable } & Coefficient & Standard error & t-value & p-value \\
\hline & Teacher variables (Level 2) & & \\
\hline Teacher job satisfaction & 12.92 & 8.87 & -1.47 & 0.142 \\
\hline \multicolumn{5}{c}{ Student variables (Level 1) } \\
\hline Learner likes learning mathematics & 10.03 & 1.46 & -6.87 & $0.000^{*}$ \\
\hline Engage teaching in math lesson & -1.42 & 1.84 & 0.77 & 0.446 \\
\hline Learner confident in mathematics & 21.26 & 2.15 & -9.89 & $0.000^{*}$ \\
\hline Learner value mathematics & 13.99 & 2.32 & -6.02 & $0.000^{*}$ \\
\hline
\end{tabular}

* Significant predictors ( $\mathrm{p}$-value $<0.05)$

The final model explains $57.07 \%$ of the variance which is significant (p-value $<0.001$ ). Thus, the final model explains $3.74 \%$ more variance than the full model. On teacher level there were no significant predictors. After removing gender from the full model, the p-value of the only remaining teacher variable has dropped from 0.262 to 0.142 , however, it is still not significant. Thus, whether or not a teacher is satisfied with his/her job, has no influence on the mathematics marks of their learners. At student level, the same three predictors are significant with their coefficients and p-values unchanged, so again, students who like learning mathematics, students that are confident in mathematics and students that value mathematics have higher marks in mathematics than those who don't.

\section{RECOMMENDATIONS AND IMPLICATIONS}

Based on the research findings on attitudinal factors associated with Grade 9 learner achievement in mathematics, the following are the recommendations made:

\section{Recommendation One}

It is worth noting that teachers' career satisfaction had no association with the mathematics achievement of their learners. For the index 'teacher job satisfaction', there were items, for example, 'I find my work full of meaning and purpose' and 'I am enthusiastic about my job'. One would think that learners who are taught by teachers 
who find their work full of meaning and purposeful and who are enthusiastic about their job, would perform better, since these teachers will put in extra effort into their teaching. Research is required to establish why this is the case.

\section{Recommendation Two}

The other element that stood out in terms of positively influencing mathematics achievement is the value that learners attach to mathematics. For the index 'student value mathematics' some of the items were, for example, 'I need to do well in mathematics to get into the university of my choice' and 'I need to do well in mathematics to get the job I want'. Thus, learners who saw the need to do well in mathematics in order to gain university entry or to get the job they wanted performed better than those who do not see the need. Therefore, it could be suggested that universities visit learners already on Grade 9 level in order to emphasise the importance of doing well in mathematics for gaining university entry and for learners' future careers. It is also suggested that, Life Orientation teachers emphasise the importance of mathematics during their career guidance lessons.

\section{SUGGESTIONS FOR FUTURE RESEACH}

Further research is required to establish the extent of frustration teachers have on learner performance in mathematics. Curriculum and policy developers should develop policies and curriculum that address the needs of all learners and teachers in an attempt to improve attitudes and perceptions related to learner performance in mathematics. Curriculum developers should conduct an intense consultation with all stakeholders with regard to curriculum change and implementation, more specifically, with teachers as they are often overlooked.

\section{REFERENCES}

Aiken, L. R. (1976). Update on attitudes and other affective variables in learning mathematics. Review of Educational Research, 46 (2), 293-311.

Ayieko, R. A.,Gokbel, E. N. \& Nelson, B. (2017). Does computer use matter? The influence of computer usage on eighth-grade students' mathematics reasoning. FIRE: Forum for International Research in Education, 4(1), 67-87.

Butakor, P. K. (2015). Multilevel modelling of factors that influence mathematics achievement in Ghana: A secondary analysis of TIMSS 2007 and 2011. Doctoral dissertation, Department of Educational Phycology, University of Alberta.

Evans, B. R. (2011). Content Knowledge, Attitudes and Self-Efficacy in the Mathematics New York City Teaching Fellows (NYCTF) Program. School Science and Mathematics, 111(5), 225-235.

Field, A. (2014). Discovering Statistics Using IBM SPSS Statistics, 4th Edition, SAGE Publishers.

Gauteng Department of Education, (2013/2014 Budget speech). Retrieved from www.education.gov.za 
Hobri, Dafik \& Hossain, A. (2018). The Implementation of Learning Together in Improving Students' Mathematics Performance. International Journal of Instruction, 11 (2), 483-496.

Kastberg, D., Roey, S., Ferraro, D. \& Lemanski, N. (2013). U.S. TIMSS and PIRLS 2011 Technical Report and User's Guide. Washington: National Center for Education Statistics.

Kiwanuka, H. N., Van Damme, J., Van Den Noortgate, W., Anumendem, D. N., Vanlaar, G., Reynolds, C. \& Namusis, S. (2016). How do student and classroom characteristics affect attitude towards mathematics? A multivariate multilevel analysis. An international Journal of Research, Policy and Practice. 1-21

Maree, K. (2010). First Steps In Research (6th ed.). Pretoria: Van Schaik Publishers.

Mullis, I. V. S. \& Martin, M. O. (Eds.) (2013). TIMSS 2015 Assessment Frameworks. Retrieved from Boston College, TIMSS \& PIRLS International Study Center website: http://timssandpirls.bc.edu/timss2015/frameworks.html

Mullis, I. V. S., Martin, M. O., Foy, P. \& Arora. A (2012). TIMSS 2011 International Results in Mathematics. Boston College: TIMSS \& PIRLS International Study Center.

PIRLS \& TIMSS (2011). Field Test Analysis of Background Questionnaire Scale Items. TIMSS AND PIRLS International Study Center, 1-3.

Reddy, V., Visser, M., Winnaar, L., Arends, F., Juan, A., Prisloo, C. H, Isdale, K. (2016). TIMSS 2015:Highlights of Mathematics and Science Achievement of Grade 9 South African learners. Human Science Research Council.

Scheerens, J. (2000). Improving school effectiveness. Fundamentals of Educational Planning series no. 68. Paris: UNESCO, IIEP.

Spaul, N. (2013). South Africa's Education Crisis: The quality of education in South Africa 1994-2011. Centre for Development and Enterprise, 1-65

Statistics South Africa, (2013 population estimates) Retrieved from www.statssa.gov.za

Tella, A. (2017). Teacher variables as predictors of academic achievement of primary school pupils' mathematics. International Electronic Journal of Elementary Education. 1 (1), 16-33

TIMSS. (2011). Highlights from TIMSS 2011. The South African Perspective, 1-12. 